\section{Land Conditions in Iraq}

Some valuable information regarding the irrigated and non-irrigated land in Traq is contained in a report by Sir Ernest Dowson on "Land Tenure and Related Questions" (Baghdad: Iraqi Government, 4s. 6d.). These statistics, which are shown also on large scale maps accompanying the report, were collected by the Irrigation Department, and show the immense possibilities for the extension of agriculture when conditions are favourable. It would appear that about twenty per cent of the total area of Iraq can be regarded as productive. This includes a northern rainfall zone covering about nine per cent, and a southern irrigation zone covering about eleven per cent. Not more than a fifth, and often as little as a tenth, of these zones are cultivated in any one year. An estimate of the rural population, for which complete accuracy is not claimed, puts the density of population so low as 19 per square kilometre in the rainfall zone, and about 35 in the most typical areas of the irrigation zones. These figures, especially the latter, are far below the potential population of the land, and compare unfavourably with the far greater density of population and higher productivity of similar lands in Egypt. Sir Ernest Dowson also comments on the lack of accurate topographical surveys in Iraq and the incompleteness of even the major triangulation. The report contains various recommendations regarding methods of land tenure, and naturally stresses, in this connexion, the need of further surveys.

\section{The Harpy at the London Zoo}

OF the two well-known and remarkable neotropical birds of prey, the condor is a familiar menagerie exhibit, but the harpy always rare: the specimen the London Zoological Gardens has recently received being only the third exhibited during this century, although the species was shown early in their career. Although commonly called an eagle from its large size, the harpy is in form, coloration, and habits a giant goshawk, allied to the tropico-politan group of hawkeagles (Spizaëtus). Like these, it presents the remarkable peculiarity of showing much more white in the immature plumage than in that of the adult; in fact, the present specimen, in its gull-like livery of white and grey, is curiously like a very different bird which is lodged next door to it in the Birds of Prey Aviarythe East Asiatic and Australasian white-bellied seaeagle (Cuncuma leucogaster). The ruff and crest of the harpy, however, give it a character quite unique among the Falconidæ, and it is this species, rather than the golden eagle, which is the analogue of the lion among beasts, especially as its feet and talons are unrivalled for size and power in the whole series of birds of prey.

\section{A 'Deaf Speaker'}

A NEW device which will aid the deaf to hear radio and gramophone music has been invented by Prof. F. Bedell, the well-known physicist of Cornell University. He calls it the 'deaf speaker' because it seryes a function similar to a 'loud speaker' in a radio set. It does not broadcast sound, but carries vibrations of the requisite amplitude and frequency to anyone who holds the receiving part of the apparatus with his teeth or pressed against his forehead or a cheekbone. From a summary of a radio talk reported by Science Service of Washington, D.C., on May 5, we learn that Prof. Bedell, working on the theory that most people who hear badly have a defective middle ear, sought to bring the sound waves to the inner ear by some other channel. He found that it could be done by bone conduction to the inner ear of the listener. It was not sufficient to transmit vibrations of the same frequency as the actual sound waves to the inner ear of the listener. They must first be adjusted to the requisite loudness and frequency. It is stated that this adjustment is substantially what takes place in the normal middle ear. Prof. Bedell's deaf speaker steps up the force of the sound waves very appreciably. Since some people are deaf to high tones and others cannot hear lower tones, the deaf speaker is provided with a device for altering the frequency. At a recent demonstration at the National Academy of Sciences, Prof. Bedell showed two kinds of receiving instruments, in one of which the receiver is held between the teeth and looks like a long tube, while the other consists of a flat disk held against the forehead or a cheekbone. The disk type has made it possible for deaf people with the aid of a microphone to hear their own voices. This apparatus is said to be very useful for teaching the deaf. It is portable, but is rather too large for everyday use.

\section{Earthquake in the Western Pacific}

A strong earthquake occurred in the western Pacific on the morning of May 14. Its records were confused with those of another earthquake in the West Indian region, but the position of its epicentre has now been determined with the arrival of additional records from seismological stations surrounding and in the Pacific. It lies in about lat. $4^{\circ} \mathrm{N}$., long. $130^{\circ} \mathrm{E}$., as determined by the seismologists of the U.S. Coast and Geodetic Survey (Wire Report of Science Service, Washington, May 16). This point lies at sea, southeast of the island of Mindanao in the Philippines. The earthquake was clearly a severe one, as it is reported to have been felt distinctly to a distance of about 600 miles from the epicentre.

\section{Congress of Quaternary Geology}

A MeEting of the Association for the Study of the European Quaternary will be held in Leningrad on Sept. 1-7. There will be two short excursions during the Congress and a long excursion from Sept. 8 until Sept. 29. Special arrangements have been made by the organising committee for the reception of members, and it is requested that geologists, arehæologists, and others who wish to attend should send in their names to the Secretary, Mr. K. Lebedev, V.O. Sredny Pr., 72-6, Leningrad 26. Particulars relating to the Congress, with programme of excursions, etc., can be consulted in the Library of the Museum of Practical Geology, 28 Jermyn Street, London, S.W.1, or at the Office of Intourist, Bush House, Aldwych, W.C.2. 